\title{
The Future of Post-COVID-19 Urban Tourism: Understanding the Experiences of Indonesian Consumers of Hallyu with South Korean Virtual Tourism
}

\author{
Riela Provi Drianda ${ }^{*}$, Meyriana Kesuma², Nadia Ayu Rahma Lestari² \\ ${ }^{1}$ School of Social Sciences, Waseda University, 1-6-1 Nishiwaseda, Shinjuku-ku, Tokyo 169-8050, Japan \\ ${ }^{2}$ Department of Architecture and Planning, Faculty of Engineering, Universitas Tarumanagara, Jl. Letjen S. \\ Parman No. 1, Jakarta Barat 11440, Indonesia
}

\begin{abstract}
Amid the outbreak of COVID-19, South Korea is still actively promoting its culture and tourist destinations to global audiences. Through the initiative of Imagine Korea Virtual Reality, the country invites foreign people to view Korean sightseeing places and tourist spots. Based on Imagine Korea as the case study material, our study attempted to identify the perceptions, feelings, and expectations of Indonesian consumers of Hallyu through virtual tourism offered by South Korea. The study employed in-depth interviews with 15 respondents who often consume Korean pop culture. The result revealed that most respondents had never experienced or had been interested in any virtual tours offered during the pandemic. Nevertheless, the experiments changed their perceptions of the entertainment virtual tours can provide throughout the COVID-19 crisis. While most respondents agreed that virtual tours sparked their interest in visiting Seoul after the pandemic ended, they mainly stated that virtual tours could never replace traditional travel. Thus, instead of serving as an alternative form of tourism during COVID-19 and afterwards, the study indicated the potential of virtual tours to be a primary destination marketing tool, one that can help visitors better design their itinerary routes and learn about local attractions.
\end{abstract}

Keywords: Hallyu consumers; Indonesia; Post-pandemic; Urban tourism; Virtual tourism

\section{Introduction}

The outbreak of COVID-19 has affected the travel and tourism sector all around the globe. As the virus continues to spread, many countries have closed their borders to international tourists. The World Tourism Organization (UNTWO) (2020) reported a significant decline in international tourist arrivals, which has caused the loss of US\$936 billion in export revenues from international tourism. The recovery of tourism receipts worldwide will take some time (OECD, 2020), as the pandemic has forced international tourism to return to the level of 30 years ago (UNWTO, 2020). In addition, many countries have suffered from economic decline and job losses due to the COVID-19 crisis in the tourism sector. Drastic losses in GDP are apparent in tourist-centric countries like Mexico, where $15.5 \%$ of the economy is dependent on the travel and tourism sector (Richter, 2020). The forum also identified Italy and Spain as among the most vulnerable countries to COVID19's impact on tourism (Richter, 2020).

As people cannot engage in traditional tourism during the pandemic, virtual tourism 
has become a new alternative for the tourism industry (Srinivasa and Krantz, 2020; Rogers, 2020). According to IGI-Global, virtual tourism can be defined as an ICT-based tool that uses digital images and sensory feedback to simulate tourist attractions available at remote destinations (IGI Global, n.d). This type of tourism enables a tourist experience without visiting the place in person. In 2002, destination marketers considered the use of virtual tours for tourism marketing (Cho et al., 2002); however, there was no precise definition of what 'virtual' means. As time went by, the popularity of virtual tourism continued to rise as it opened up the possibility to visit protected or impossible-to-visit sites (Wagler and Hanus, 2018). Heritage destinations are often threatened by tourism activity (Widaningrum et al., 2020), and virtual tours could help preserve these endangered sites. Additionally, virtual tours could also help visitors experience the destination's selected visual, audio, and spatial aspects without actually being there (Yung and Lattimore, 2019). Virtual tourism is also safer and more secure, as users do not have to deal with jetlag, the risk of contracting diseases, and other dangers and discomforts (Srinivasa and Krantz, 2020).

During the wide and continuous spread of the coronavirus, many countries are trying various interventive measures to save their tourism through a rapid shift to digitalization. Virtual tours, which will be discussed in this study, emerged as an innovative solution to address the challenges faced by the tourism sector during the global spread of COVID-19. Its development was intended to assist the traditional tourism and cultural sectors hit hard by the pandemic. Various countries have been developing virtual tours to keep their cultures alive. However, in this study we focus on the tours developed by South Korea as one country that has been actively using virtual tours to attract potential holidaymakers. The outbreak of COVID-19 has not stopped the country from promoting its cultural and historical assets to potential holidaymakers. Instead, the Korean Tourism Agency (KTO) has aggressively branded South Korea tourism through various virtual tours and promotional videos, despite the continuous worldwide spread of coronavirus. By looking at the virtual tours developed by the Korean Tourism Organization, this study intended to identify the extent to which they could provide users, in this context Indonesian consumers of Hallyu, with tourism experience. In addition, this study focused on the experiences of Indonesian consumers of Hallyu while considering the increased number of Indonesians who consumed Korean pop culture during the pandemic (Drianda et al., 2021). Further, the study attempts to identify whether Indonesian tourism stakeholders should consider virtual tourism for the future of post-pandemic tourism. Finally, it also seeks to fathom the lessons learned in order to recommend improvement of the design of virtual tours to optimize the tourism experience.

\section{An Introduction to Hallyu and Hallyu Tourism}

The Korean wave, or Hallyu, a term coined by a Chinese journalist in 1991, refers to the growing popularity of Korean entertainment and popular culture in other Asian countries and now the world. Within years, it has gained tremendous worldwide popularity and set an example of how culture can be considered as a country wielding soft power. South Korea is no longer identified as an insignificant Asian country, as its blossoming economy has freed it from the image of a war-torn country (Kinsey and Chung, 2013). The country is now seen, thanks to its unique and influential pop culture, as a rapidly developed Asian country with remarkable economic power and an advanced society.

Harnessing the Korean Wave, the government has been actively promoting Hallyu Tourism. While to date, there is no clear definition of Hallyu Tourism, Lee and How (2021) argued that this type of tourism has been induced by the growing interest of global tourists 
in Korean film, celebrities, food, and culture. The Korean government has aggressively exported their cultural products to overseas countries, including the growing countries of Southeast Asia (Miji, 2010). As a result, the consumption of Korean culture abroad is soaring significantly, influencing international travelers to visit South Korea (Bae et al., 2017). Martin Roll (2021) estimated that Hallyu had contributed to a boost of USD 12.3 billion to its economy in 2019. While the government had ambitions to increase the number of inbound tourists (KBS, 2020), their plans were thwarted by the COVID-19 pandemic. However, the Korea Tourism Organization (KTO) responded promptly, creating virtual tours for global audiences. Following the KTO, other government bodies and museums also offer virtual tours to reinvigorate the tourism industry and maintain their cultural soft power over global audiences. However, in this study, we will limit the observation to the tours offered by KTO through its series of Imagine Korea virtual tours.

\section{Methods}

The study employed an in-depth interview methodology to obtain information. An indepth interview enables the respondents to engage in a relaxed, open, and honest discussion with the interviewer (Morris, 2015). The interview comprises open-ended questions that allow the interviewer to discover more detailed information about a specific topic (Wallace Foundation, n.d). This method is argued as being highly effective for obtaining data for social research (Morris, 2015). Fifteen female respondents were recruited through convenience sampling. The selected respondents are all of similar backgrounds: they are fans of Korean pop culture, including Korean drama and pop music. They range in age from 20 to 39 years old. Respondents were given the option to be interviewed through online calls or message texting for approximately one to two hours. The surveyors recorded all the conversations with the consent of the respondents. Most respondents accessed the tour through their notebooks $(9 / 15)$, while the others used their tablets $(3 / 15)$ or smartphones $(3 / 15)$.

As for the online interview, it was later transcribed into written text. Before participating in the in-depth interviews, respondents were asked to view the Imagine Your Korea homepage, which offers ten virtual tours, including a tour to the UNESCO Heritage Site Andong, and a Gangnam K-Pop Tour. The Imagine Korea virtual tours enable users to access the tours without registering for membership (see Figure 1).

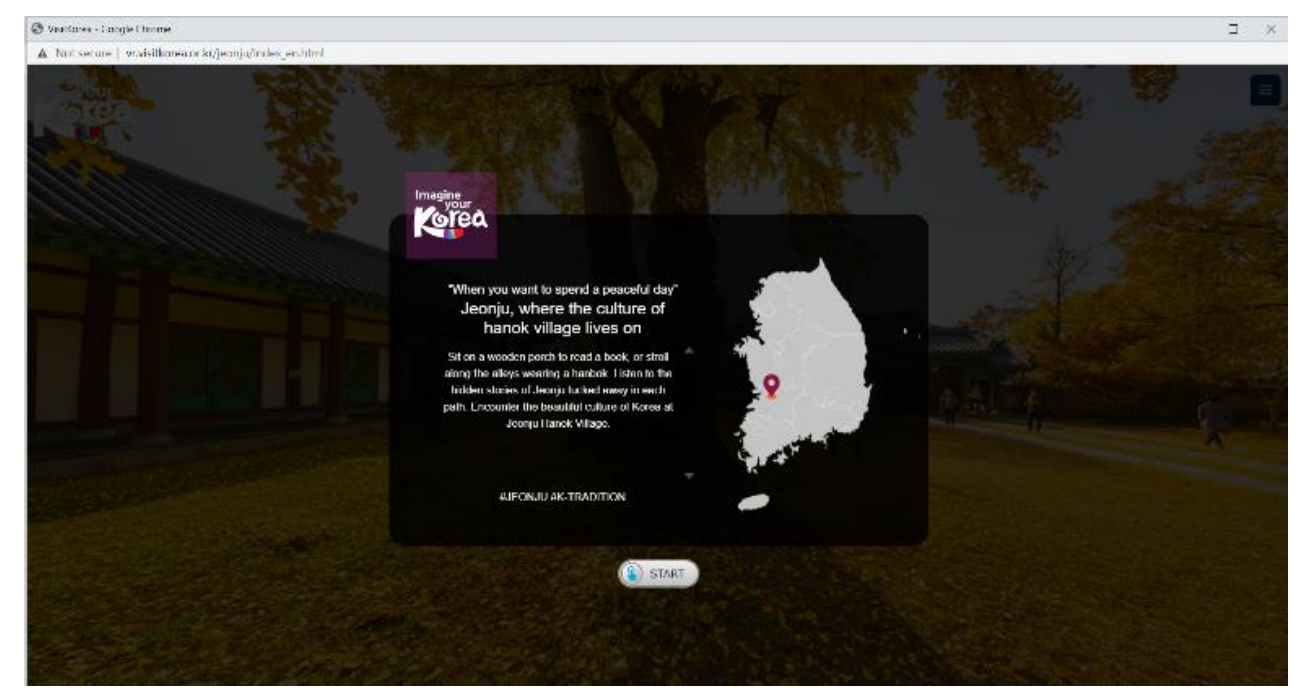

Figure 1 An example of a virtual tour of imagine your Korea. Imagine Your Korea (n.d.). K-tradition Tour (screen capture). Retrieved from, http://vr.visitkorea.or.kr/jeonju/index_en.html 
In principle, anyone can visit the website and explore the tours for free. Users can use their PC, laptop, tablet, or smartphone to explore the provided tours. After clicking 'start' for the selected virtual tour, users can explore a number of scenes portraying the uniqueness of each destination area. A brief explanation box, including some travel tips, is provided at each scene. Users can also view 360-degree images by moving the cursor.

In this study, all respondents were asked to view two virtual tours uploaded on Imagine Korea at a time convenient to them. No time limit was imposed, considering the respondents' busy schedules. They were allowed to use any device that they possessed and were requested to contact the interviewer when they had finished the exploration. After this, the interviewer proceeded with the data-collection process, preparing a semistructured list of questions to allow for a better interview process. The questions include the following aspects: (i) respondent's knowledge regarding virtual tours; (ii) respondent's previous experience of virtual tourism; (iii) respondent's first impression of the Imagine Korea virtual tour; (iv) perceptions of the strengths and weaknesses of virtual tours; and (v) respondent's opinion regarding virtual tours as an alternative for post-pandemic tourism in the future. Thematic analysis was used to identify important patterns in the data, leading to interesting findings to obtain conclusions and answer the questions posed in the aims and objectives of this study (Cartwright, 2020). The analysis process followed inductive coding, where researchers develop codes from the phrases and terms uttered by the participants (Linneberg and Korsgaard, 2019).

\section{Results and Discussion}

This section focuses on the in-depth interview results, which were analyzed thematically. The resulting interpretations are presented along with the discussion on important key themes (see Figure 2).

\subsection{Prior Experience with Virtual Tourism}

The study identified the unpopularity of virtual tourism among the interviewed Indonesian consumers of Hallyu. Before the interview, most of them had never tried any virtual tour from foreign or domestic tour providers. Despite the booming virtual tours offered by the Indonesian museum and cultural institutions during the pandemic, none of the respondents showed any interest in such expeditions. In the same way, all respondents were not aware of the free virtual tours provided by the South Korean government. In contrast to Pourmoradian et al. (2021), who discovered a rise in users exploring virtual tours during the beginning phase of the pandemic, this study revealed that Indonesians have limited experience with virtual tourism, despite the availability of such services, which can be accessed free of charge.
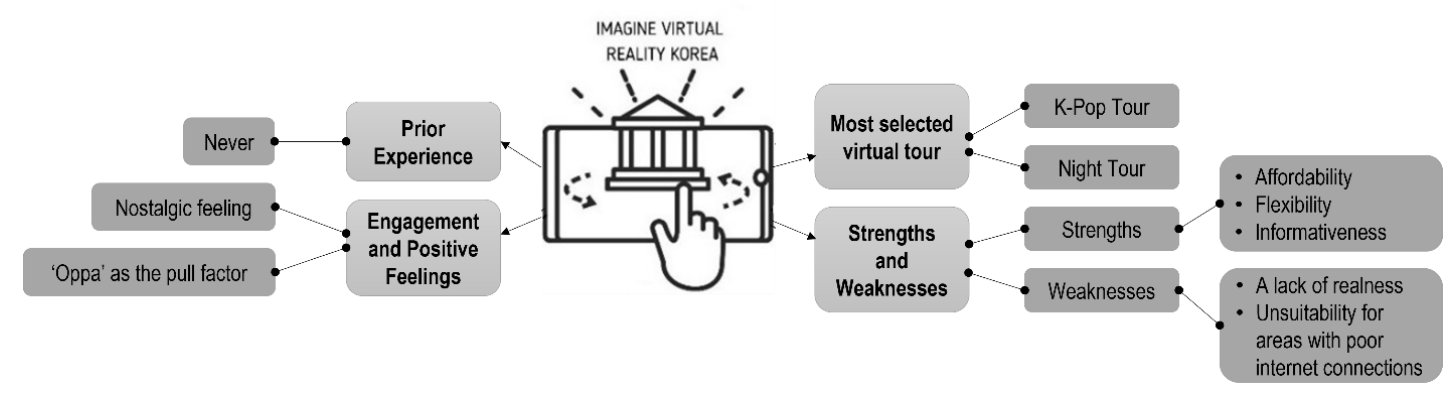

Figure 2 The key themes extracted from in-depth interviews

\subsection{The Most Selected Virtual Tours}

Out of the ten thematic virtual tours provided on the Imagine Virtual Reality South Korea page, we identified two tours most often selected by respondents. The first is the 
Gangnam K-pop tour, a selection which verified the interest of the research respondents in Korean pop culture. The name "Gangnam" is no longer foreign to non-Korean citizens thanks to PSY's parody song that criticized the polarization of wealthy people in the Gangnam area of Seoul (Kuwahara, 2014). The growing popularity of the Gangnam area led the government of Gangnam District to launch a flagship project named K-star Road. The road features many GangnamDols, symbolic sculptures of famous K-pop idol groups such as EXO, Super Junior, BTS, and Girls' Generation. This flagship project was aimed at attracting more foreign visitors to the area to advance Gangnam's attempts to create a global city (Oh, 2021). This study confirmed that Indonesian consumers of Hallyu are familiar with Gangnam's branding as the centre of Korean pop culture.

The second-most selected tour was the Night Tour, featuring Namsan Tower. It was built in 1971 as a communications and observation tower, providing TV and radio broadcasting to the capital city of South Korea. The tower is a familiar backdrop in many Korean dramas, such as Boys Over Flower, Korean Odyssey, and the recent drama True Beauty. It is often used as the date spot for couples in Korean drama, and the setting for the stock unrequited love scene. Due to its frequent appearances in all genres of Korean dramas, it is not surprising to discover that our respondents selected Namsan Tower as their second virtual tour (See Figure 3). Many cities have used iconic buildings or architecture to distinguish themselves from others. Indeed, the trend has shown how modern cities tend to build and use iconic artefacts to enrich their branding (Elhagla et al. 2020), and it is apparent that Namsan Tower has successfully represented Seoul among the global society, becoming a top tourism destination.

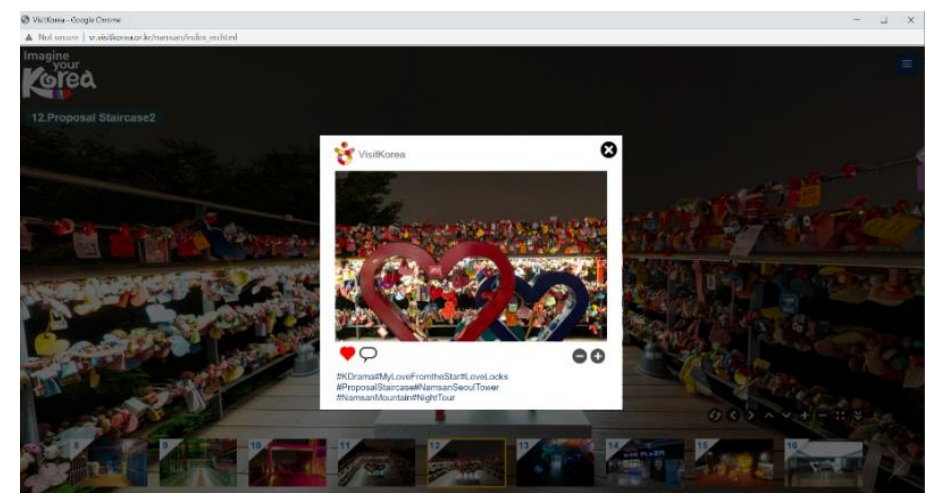

Figure 3 Interactive virtual tour featuring Namsan Tower and its environs. Imagine Your Korea (n.d.). Night Tour (screen capture). Retrieved from

http://vr.visitkorea.or.kr/namsan/index_en.html

\subsection{Engagement and Positive Feelings Experienced throughout the Tour}

\subsubsection{Oppa as a pull factor of virtual tourism}

We identified positive feelings of the respondents when exploring both the Gangnamand Namsan-themed virtual tours. While most of them praised the high technology enabling them to travel virtually to Seoul, some respondents mentioned their idols' cardboard cutout because they enjoyed the tour.

It is really dangerous to go alone. I might get lost in the city. There are too many cutout that make my heart flutter every time I see them. It is hard to decide where to go. I am unsure whether I will stick to my itinerary plan, or maybe just go wherever my Oppa [cutout] are (Female respondent, age 28). 
Other than cardboard cutout, some respondents also emphasized Seoul as "Oppa Land". According to learnkorean24, Oppa is used by Korean women to refer to an older man such as older brothers or cousins, boyfriends, or anyone they are close to and can trust (Learn Korean 24, n.d). However, the rising popularity of the Korean Wave has led many foreigners to call random male celebrities or handsome Korean males "Oppa", and this is considered unseemly by native Koreans and those who understand Korean culture. Nonetheless, the study verified the power of Oppa to attract foreigners to consume Korean culture. Our respondents frequently mentioned the word Oppa when describing the positive feelings they experienced during the virtual tour. For instance, they were pleased to see giant advertising billboards at Gangnam displaying their favorite K-pop stars. This finding verified Lee and How (2021), who identified Korean celebrities as one of the strongest pull factors for recent Korean inbound tourism.

\subsubsection{Feelings of nostalgia and the desire to travel}

A few respondents who had travelled to Seoul conveyed their nostalgia when looking at the pictures of Namsan Tower, the Namsan Tower's love locks, and other cityscapes. One respondent stated how she was happy to see the Namsan Tower's love locks, as they brought back beautiful memories from her last visit to Seoul. Leong et al. (2015) indicated that a desire for nostalgia among tourists could be among the factors attracting them to travel to a particular place. This study recognized a similar desire among the respondents to travel again to Seoul after seeing some familiar spots and items in the virtual tours.

“... The VTs are really impressive. I am impressed because I have been to Korea, and now (after looking at) the VTs, I feel some kind of nostalgic feeling, so I tracked down many places, and yes, I want to go again" (Female respondent, age 28).

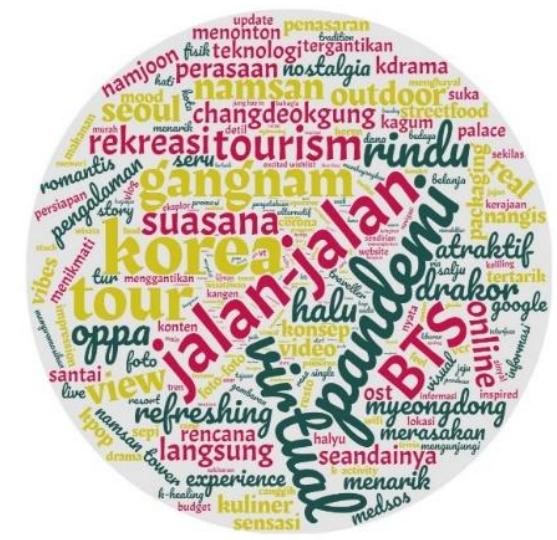

Figure 4 Wordcloud analysis indicating the respondents' desire to travel to South Korea

Figure 4 displays the words most frequently mentioned by the respondents after exploring the VTs. Through these words the respondents showed an interest in visiting Korea after the pandemic ends, reflecting a desire to visit places featured in Korean dramas, find their idols such as BTS and other celebrities they defined as "Oppa", and also go shopping. The figure captures a number of places that respondents want to visit in person, such as Gangnam, Namsan, Seoul, and Changdeokgung Palace. How the respondents expressed their desire to travel after exploring the Imagine Your Korea virtual tour reveals the potential of these virtual tours to attract potential holidaymakers. Thus, it appears that to some extent, the mission of the Seoul City Government to lure Hallyu fans to visit Seoul when the pandemic subsides through the distribution of promotional materials (HabKorea, 2020) could be considered a success, as all respondents became more interested in visiting Korea after consuming the VTs. Throughout 2020, the Seoul City Government launched 
several promotional materials to attract viewers to gaze at the various activities they can partake in and the spots they can visit after the coronavirus pandemic. Aside from the Imagine Korea's virtual tours examined in this study, the Seoul City Government has also teamed up with K-pop idols such as BTS, Cha Eun Woo, and Seventeen to promote attractions of the city both famous and hidden. Lately, since the boom of the Korean Wave, the strategy to use K-pop idols for urban and rural promotion has become quite common in South Korea (Oh, 2021).

\subsection{Strengths and Weaknesses of Virtual Tourism}

\subsubsection{Strengths of virtual tourism}

Virtual tourism can be used as a substitute to avoid the drawbacks that may arise with traditional tourism, such as lack of time and money, and safety concerns (Guttentag, 2010). As the virtual tour is accessible by computer, anyone with internet access can use it. Several respondents mentioned the virtual tours offered easy access, as there was no need to log in or register to start the exploration. They also emphasized how the virtual tours offered by Imagine Your Korea saved them money and time. It enables those under financial constraints to at least virtually enjoy Korea.

Rather than never having the chance to see Korea, at least with this VT, you know the corner where you can see their [BTS'] cardboard cutout (screams happily) (Female respondent, 28)

The above statement indicates how virtual tours are an option for those who lack the time and money to engage in traditional tourism. A virtual tour is flexible, it can be accessed while doing something else, and it is not constrained by time as it can be taken anywhere. Most respondents agreed that virtual tours could help them to navigate Seoul before visiting the city in person. They feel that the detailed pictures and directions presented in the tour would enable them to conduct pre-research before developing their "bucket-list" destinations. Those who have never been to Seoul described how the virtual tour helped them identify and familiarize themselves with the available attractions. Some respondents further mentioned how the tour enabled them to plan their dream itinerary in advance. Similar responses were given by those who had visited Seoul in person, all of whom agreed that virtual tours could help them plan better travel itineraries. As put by one respondent,

The last time I went there, I didn't notice that Namsan Tower has a lot of interesting stores. But, after looking at the virtual tour, I realized that I should have visited those stores. So, if I have another chance to visit Seoul, I will definitely check them out (Female respondent, 29).

Additionally, most respondents pointed out the high-quality images and some of the interactive features of the virtual tours, such as interactive photo-spot functions that allow users to screenshot their virtual experience at designated places. Moreover, the narratives are perceived as clear and engaging, giving the impression the tours are designed with Hallyu fans in mind.

\subsubsection{Weaknesses of virtual tourism}

Imagine Korea's virtual tours indeed provides high-quality pictures and quite detailed images about the destination. However, despite the virtual tours' offer of advanced technologies and unique experiences, most respondents believe they could never replace traditional travel. According to some respondents, they feel the virtual tour is less authentic. They missed the opportunities to taste real food and see real people.

I don't think virtual tourism can fully replace traditional tourism. When you travel, there are feelings and emotions involved. For example, I can say, 'I have been here', instead of 'I have 
seen this on my computer. We also can't taste the food unless we go there (Female respondent, 28).

Aside from feelings and emotions, two respondents pointed out how there was no audio during the tour, such as the sounds of the surrounding environment or even simple Korean greetings, indicating the tour lacked something.

At first, I thought that I would hear something... [but] it is very silent, so I can't capture the feeling... it would be much better if they played audio, such as birds singing, or the sound of the wind and swaying trees (Female respondent, 30).

Our study verified that virtual tours would be more attractive and useful if they were supported with audio and more interactive buttons. Virtual tours could be combined with an introductory video to provide background and describe the features of these sites to increase the emotional engagement, as asserted by Wagler and Hanus (2018). Other respondents also mentioned a lack of realness in the virtual tours. Although they could spend time exploring an area, they could not explore another side of a street which they might find appealing. Additionally, virtual tours could not provide the cultural experiences offered by traditional travel. Tourism is a social and cultural event, in which direct interactions are important for tourists (Cheong, 1995), whereas virtual tourism does not yet provide this kind of experience. This finding is in line with El-Said and Aziz (2021) and Chen (2020), who argued that virtual tours would never replace traditional tours.

Aside from the lack of realness, few respondents also believed that advanced virtual tours might not be suitable for developing countries, especially cities without good internet connections. None of the respondents mentioned any problems related to the device they used for the virtual tours, but a few respondents underlined issues surrounding their internet connections. They admitted that they stopped exploring the virtual tours and just focused on the static images displayed on the website. Their cases highlighted the difficulty a viewer might experience without access to a good internet connection.

\section{Conclusions}

The study recognized the potential of virtual tours to attract people's interest in tourist destination sites during the COVID-19 pandemic. Therefore, virtual tours should be considered as a potential marketing tool for urban tourism, in light of their power to generate short bursts of enjoyment, nostalgic feelings, and even to spark a desire to visit Seoul. However, the study reminded us of aspects that could not be replaced by a virtual tour: the desire of tourists to connect with real people, taste the food, and experience the culture directly. Therefore, this study suggests investing in the development of virtual tourism as a tool for the marketing of a city. In addition, the present study identified some lessons learned regarding the design of Imagine Your Korea virtual tours. The first is related to the quality of images used in the virtual tours: All images are presented in high resolution, enabling the users to see the scene clearly in detail. The closer the image is to reality, the greater the tendency for users to be interested in the promoted area. The second concerns the design of the content and narratives. Imagine Your Korea offers users ten thematic tours, allowing them to explore Korea with explanations from different points of view. The designers focus on providing images that they believe would attract potential holidaymakers, particularly Hallyu fans. The case of Imagine Your Korea taught us the importance of developing attractive narratives that could spark users' interest in visiting the promoted area in person. The third lesson concerns easy access for users to explore the virtual tour, such as eliminating the need to log in, register, or use a specific device to explore the tour. Nevertheless, some of the input from the respondents of this study can be 
considered in optimizing the tourism experience. The first of these improvements concerns adopting mixed reality, a hybrid of virtual reality and augmented reality, to accommodate users' expectations for a near-realistic tourism experience. However, this adoption might lead to the second suggestion, which focuses on providing an alternative virtual tour for those with limited access to an internet connection. The respondents in this study who could not access the tour due to a poor wi-fi connection decided not to explore it. It would thus be a waste to invest in virtual tours that potential holidaymakers cannot access. Finally, this study emphasizes the importance of speeding up the provision of digital infrastructure to enable more innovation in future cities, as suggested by Berawi (2018; 2021).

\section{Acknowledgements}

We would like to thank our respondents for devoting their time to the study, and for sharing their perspectives on the virtual tours studied.

\section{References}

Bae, E.S, Chang, M., Park, E.S., Kim, D.C., 2017. The Effect of Hallyu on Tourism in Korea. Journal of Open Innovation: Technology, Market, and Complexity. Volume 3(22), pp.1-12

Berawi, M.A., 2021. Innovative Technology for Post-Pandemic Economic Recovery. International Journal of Technology. Volume 12(1), pp. 1-4

Berawi, M.A., 2018. The Fourth Industrial Revolution: Managing Technology Development for Competitiveness. International Journal of Technology, Volume 9(1), pp. 1-4

Cartwright, L., 2020. Using Thematic Analysis in Social Work Research: Barriers to Recruitment and Issues of Confidentiality. London: SAGE Research Methods Cases, SAGE Publications, pp. 1-12

Chen, A., 2020. Is Virtual Travel Here To Stay, Even After the Pandemic Subsides? Available Online at https://www.nationalgeographic.com/travel/article/can-virtual-realityreplace-real-tourism-during-pandemic-and-beyond, Accessed on May 20, 2021

Cheong, R., 1995. The Virtual Threat to Travel and Tourism. Tourism Management, Volume 16(6), pp. 417-422

Cho, Y., Wang, Y., Fesenmaier, D.R., 2002. Searching for Experiences. Journal of Travel \& Tourism Marketing, Volume 12(4), pp. 1-17

Drianda, R.P., Kesuma, M., Lestari, N.A.R., 2021. K-Wave Content as a Source of Comfort during the Coronavirus Widespread in Indonesia. In: Proceedings of the International Conference on Economics, Business, Social, and Humanities 2021, 17-18 February, Jakarta

Elhagla, K., Nassar, D.N., Ragheb., 2020. Iconic Buildings' Contribution toward Urbanism. Alexandria Engineering Journal, Volume 59(2), pp. 803-813

El Said, O. and Aziz, H., 2021. Virtual Tours a Means to an End: An Analysis of Virtual Tours' Role in Tourism Recovery Post COVID-19. Journal of Travel Research. Onlinefirst

Guttentag, D.A., 2010. Virtual Reality: Applications and Implications for Tourism. Tourism Management, Volume 31(5), pp. 637-651

HabKorea, 2020. 'See You in Seoul': BTS Promotes Seoul Tourism. Available Online at https://www.habkorea.net/see-you-in-seoul-bts-promotes-tourism

IGI Global, nd. https://www.igi-global.com/dictionary/virtual-tourism/60244, Accessed on May 20, 2021

KBS, 2020. Korea Aims to Attract 20 Million Foreign Tourists in 2020. Available Online at https://world.kbs.co.kr, Accessed on May 20, 2021 
Kinsey, D.F., Chung, M., 2013. National Image of South Korea: Implications for Public Diplomacy. The Journal of Public Diplomacy, Volume 4(1), pp. 1-12

Kuwahara, C.S., 2014. "Gangnam Style" as Format: When a Localized Korean Song Meets a Global Audience. In: The Korean Wave: Korean Popular Culture in Global Context, Palgrave Macmillan, London, pp. 101-116

Learn Korean 24, nd. What does Oppa Mean? Available Online at https://learnkorean24.com/what-does-oppa-mean, Accessed on May 20, 2021

Lee, C.G., How, S.M., 2021. Hallyu Tourism: Impacts on Inbound Tourists to South Korea. Current Issues in Tourism, pp. https://doi.org/10.1080/13683500.2021.1924637

Leong, A.M., ShuoYeh, S., Yu, C., Huan, T.C., 2015. Nostalgia as Travel Motivation and Its Impact on Tourists' Loyalty. Journal of Business Research, Volume 68(1), pp. 81-86

Linneberg, M., Korsgaard, S., 2019. Coding Qualitative Data: A Synthesis Guiding the Novice. Qualitative Research Journal, Volume 19(3), pp. 2-27

Martin Roll, 2021. Korean Wave (Hallyu)-The Rise of Korea's Cultural Economy \& Pop Culture. Available online at https://martinroll.com/resources/articles/asia/koreanwave-hallyu-the-rise-of-koreas-cultural-economy-pop-culture/, Accessed on December 3, 2021

Miji, L., 2010. Korean Wave (Hallyu) Promotion Policies of the South Korean Government towards Southeast Asia: The Export of Korean Television Dramas to Vietnam and Thailand. Tounan Ajia Kenkyuu, Volume 48(3), pp. 265-293

Morris, A., 2015. The What and Why of In-depth Interviewing. In: A Practical Introduction to In-depth Interviewing, SAGE Publications, pp. 1-16

Oh, Y., 2021. Pop City: Korean Popular Culture and the Selling of Place. Cornell University Press, New York

Pourmoradian, S., Farrokhi, O.S., Hosseini, S.Y., 2021. Museum Visitors' Interest on Virtual Tours in COVID-19 Situation. Journal of Environmental Management \& Tourism. Volume 12(4), pp. 877-885

Richter, F., 2020. COVID-19: These Countries are Most at Risk from Falling Tourism. Available Online at https://www.weforum.org/agenda/2020/07/coronaviruscovid19-travel-tourism-gdp-economics, Accessed on May 20, 2021

Rogers, S., 2020. How Virtual Reality Could Help the Travel and Tourism Industry in the Aftermath of the Coronavirus Outbreak. Available Online at https://www.forbes.com/sites/solrogers/2020/03/18/virtual-reality-and-tourismwhats-already-happening-is-it-the-future/?sh=7c5a787528a6, Accessed on May 20, 2021

Srinivasa Rao, A., Krantz, S.G., 2020. Data Science for Virtual Tourism using Cutting-Edge Visualizations: Information Geometry and Conformal Mapping. Patterns, Volume 1(5), pp. 1-4

UNWTO, 2020. Tourism and COVID-19-Unprecedented Economic Impacts. Available Online at https://www.unwto.org/tourism-and-covid-19-unprecedented-economicimpacts, Accessed on June 2, 2021

Wallace Foundation, nd. Workbook E: Conducting In-Depth Interviews. Available Online at https://www.wallacefoundation.org/knowledge-center/Documents/Workbook-EIndepth-Interviews.pdf

Wagler, A., Hanus, M.D., 2018. Comparing Virtual Reality Tourism to Real-Life Experience: Effects of Presence and Engagement on Attitude and Enjoyment. Communication Research Reports, Volume 35(5), pp. 456-464 
Widaningrum, D.L., Surjandari, I., Sudiana, D., 2020. Analyzing Land-Use Changes in Tourism Development Area: A Case Study of Cultural World Heritage Sites in Java Island, Indonesia. International Journal of Technology, Volume 11(4), pp. 688-697

Yung, R., Lattimore, C.K., 2019. New Realities: A Systematic Literature Review on Virtual Reality and Augmented Reality in Tourism Research. Current Issues in Tourism, Volume 22(17), pp. 2056-2081 